CASE REPORT

Volume 14 Issue 22019

DOI: 10.21315/aos2019.14.2.372

ARTICLE INFO

Submitted: 06/03/2019

Accepted: 05/09/2019

Online: 30/12/2019

\section{Endodontic Management of a Mature Mandibular First Permanent Molar That Survived for 20 Years after Complete Pulpotomy: A Case Report}

\author{
Galvin Sim Siang Lin, Nik Rozainah Nik Abdul Ghani, \\ Kasmawati Mokhtar, Mohamad Syahrizal Halim \\ Unit of Conservative Dentistry, School of Dental Sciences, \\ Universiti Sains Malaysia, Health Campus, 16150 Kubang Kerian, \\ Kelantan, Malaysia \\ ${ }^{\star}$ Corresponding author: rozainah@usm.my
}

To cite this article: Lin GSS, Nik Abdul Ghani NR, Mokhtar K, Halim MS (2019). Endodontic management of a mature mandibular first permanent molar that survived for 20 years after complete pulpotomy: A case report. Arch Orofac Sci, 14(2): 169-175. https://doi.org/10.21315/aos2019.14.2.372

To link to this article: https://doi.org/10.21315/aos2019.14.2.372

\begin{abstract}
Complete pulpotomy as a treatment option for caries exposure in mature permanent teeth with complete root formation still remains controversial due to lack of evidence on the long-term success. This article highlights a rare complete pulpotomy case done on a mature permanent tooth that survived for 20 years. A 34-year-old female presented with dull spontaneous pain on her right mandibular first molar and showed positive response to both cold test and electrical pulp test. The tooth was previously restored with tooth coloured restoration at the disto-occlusal surface and pre-operative periapical radiograph revealed large radiopacity covering the entire pulp chamber with calcified canals. The tooth was diagnosed as previously initiated therapy with symptomatic apical periodontitis. Endodontic treatment was initiated. All canals were located and corrected working length achieved followed by cleaning and shaping using HyFlex CM rotary files with copious irrigation of $2.5 \%$ sodium hypochlorite solution. Intracanal medication (non-setting calcium hydroxide) was placed and the tooth was restored with temporary restoration. After two weeks, obturation was done using single cone technique with EndoRez sealer. Universal composite resin was placed as permanent restoration and follow-up was done after one month and three months respectively without symptoms and evidence of periapical lesion. This minimally invasive pulpotomy procedure may be an alternative treatment option for mature permanent teeth whenever carious exposure to the pulp occurs.
\end{abstract}

Keywords: Calcified canals; endodontic treatment; HyFlex CM; mature permanent teeth; pulpotomy.

\section{INTRODUCTION}

Pulpotomy in primary teeth and immature permanent teeth has been practiced by many clinicians for decades whenever there is carious exposure to the pulp. Root canal treatment is not encouraged in such situation as obturation will inhibit the physiologic dentine deposition which exposes the thin canals to a higher chance of fracture (Fong and Davis, 2002). Therefore, it is recommended that the tooth should undergo endodontic treatment once root development is completed. Pulpotomy is less preferred in mature permanent teeth with pulp exposures due to caries as this vital pulp therapy does not have solid evidence to support their role in this situation and only complete root canal 
therapy can ensure the removal of bacteria invading the pulp tissue (Taintor et al., 1981).

Zinc oxide eugenol has a long history as capping material in vital pulpotomy due to its good sealing ability, analgesic, antiinflammatory and antibacterial properties (Tchaou et al., 1995). Studies also revealed promising results of pulpotomy using zinc oxide eugenol in both primary teeth and immature permanent teeth (Gonzalez-Lara et al., 2016). However, pulpotomy in mature permanent teeth with completely formed roots had raised concerns in endodontics with no undisputed answer to this issue till date. Recently, many new biomaterials such as MTA have been studied as pulp capping materials in partial or complete pulpotomy for mature permanent teeth with promising results after up to 18 months follow-up (Asgary et al., 2016; Kang et al., 2017).

This article reported a rare case of a mature permanent mandibular first molar with completely formed roots that survived for 20 years after complete pulpotomy was performed and zinc oxide eugenol placed as dressing material.

\section{CASE REPORT}

A 34-year-old female patient was presented at the Universiti Sains Malaysia (USM) dental clinic with a chief complaint of dull spontaneous pain on her lower right posterior tooth for the past three weeks. The pain intensity increased in the last two days but did not radiate to the other areas. She gave the pain score of 6 out of 10 and claimed that the pain worsens when she tried to lie down on her bed. Besides, she also mentioned that the specific tooth was restored by a dentist 20 years ago at one of the private clinics in her hometown but no further follow-up was given. Specific examination was done on tooth 46 and upon inspection, the tooth was restored with a tooth coloured restoration at the disto-occlusal (DO) surface (Fig. 1) with no sign of swelling or sinus tract. Surrounding gingiva was normal with no pocket. The tooth exhibited no tenderness to palpation but slightly tender to percussion and no mobility was observed. Furthermore, tooth 46 had positive response to cold test and slightly delayed response to electric pulp test (EPT) as compared to the control tooth 36. Patient experienced a sharp pain after removal of cold stimulus for about 15 seconds. A preoperative periapical radiograph was taken and revealed large radiopaque material covering the entire pulp chamber area. The mesial and distal canals seemed to be calcified on the preoperative conventional radiograph with no sign of periapical pathology. Tooth 46 was diagnosed as previously initiated therapy with symptomatic apical periodontitis. Root canal therapy was planned as the treatment for the present case.

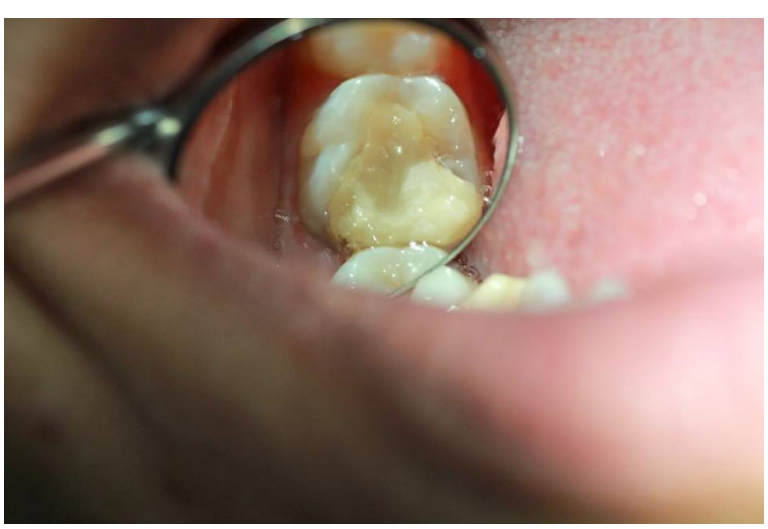

Fig. 1 Tooth coloured restoration on disto-occlusal surface of tooth 46 .

After verbal and written consent obtained from the patient, topical Benzocaine was applied followed by one cartridge of local with $2.2 \mathrm{ml}$ of mepivacaine and epinephrine 1: 100,000 (Scandonest, Septodont, France) administered via inferior alveolar nerve block. A metal molar band \#27 (DynaFlex, Missouri, USA) was placed on the tooth 46 to prevent the tooth from fracturing under function secondary to extensive loss of tooth structure. Rubber dam isolation was set up and access cavity was done. A layer of zinc oxide eugenol was noted about $3 \mathrm{~mm}$ thick beneath the temporary restoration and the remaining zinc oxide eugenol close to the 
floor of pulp chamber was further removed with a spoon excavator (NO.18, SMS-111746, Nazmed SMS, Malaysia). Four canals were located. Besides, bleeding was also noted from the mesiobuccal, mesiolingual and distolingual canals and haemostasis achieved with placement of cotton pellet soaked with normal saline solution for $10 \mathrm{~min}$ and pulp extirpated followed by irrigation using $10 \mathrm{ml}$ of $2.5 \%$ sodium hypochlorite $(\mathrm{NaOCl})$ solution. After that, glide path was achieved using K-files starting from size 6 and further increased to size 8, 10 and 15 (Kerr Corporation, Orange, CA, USA) with the aid of chelating agent (Glyde $^{\mathrm{TM}}$, Patterson Dental Supply, Inc., USA). Working lengths were determined with the use of Apex locator (Root ZX, Morita, Tokyo, Japan) and confirmed with a periapical radiograph (Fig. 2). All four canals were cleaned and shaped with HyFlex CM rotary files (Coltene, Altstätten, Switzerland) (Fig. 3) until file No.5 30/04 with the used of Endo A Class Endodontics Motor (Saeyang, Daegu, Korea).

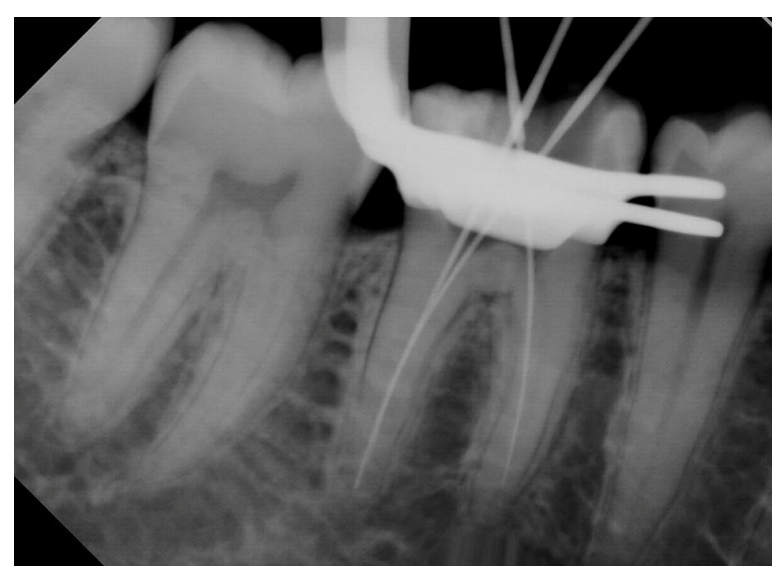

Fig. 2 Periapical radiograph of tooth 46 with K-file size 10 determining the working length.

Copious irrigations were performed with $2.5 \%$ sodium hypochlorite solution (NaOCl) (Clorox Germicidal Bleach, Clorox Company, CA, USA) and rinse with 17\% Ethylenediaminetetraacetic Acid (EDTA) solution (Sigma-Al-drich, St. Louis, MO, USA) to remove smear layer. Root canals (Fig. 4) were dried with sterile paper points (Dentsply, Maillefer, USA). Non-setting

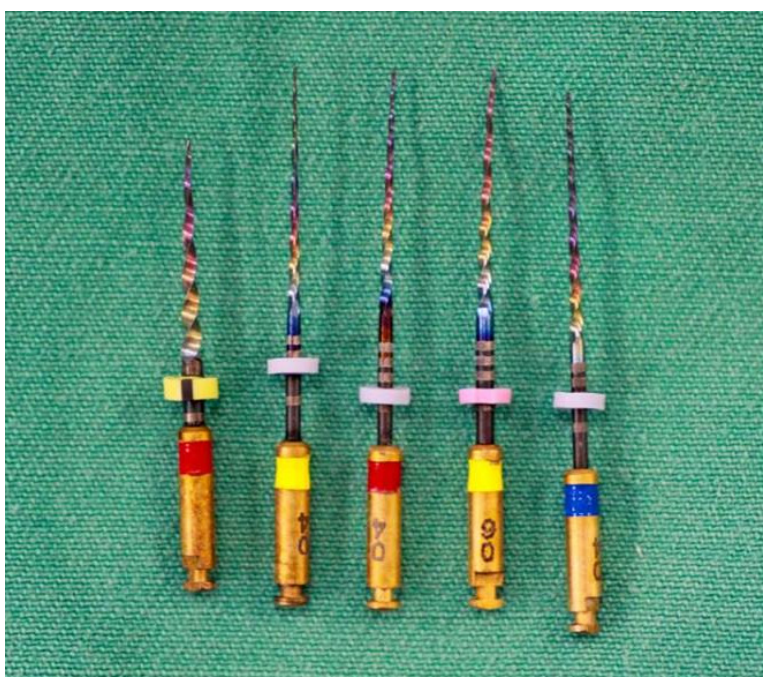

Fig. 3 HyFlex CM rotary files used in cleaning and shaping on canals.

calcium hydroxide (Multi-Cal ${ }^{\mathrm{TM}}$, Patterson Dental, Canada) was used as intracanal medication, followed by a sterile cotton pellet and Cavit (3M ESPE AG, Seefeld, Germany). Glass ionomer cement Fuji IX (GC America Inc., USA) used as a temporary restoration to cover the access cavity. Patient was scheduled for obturation after two weeks.

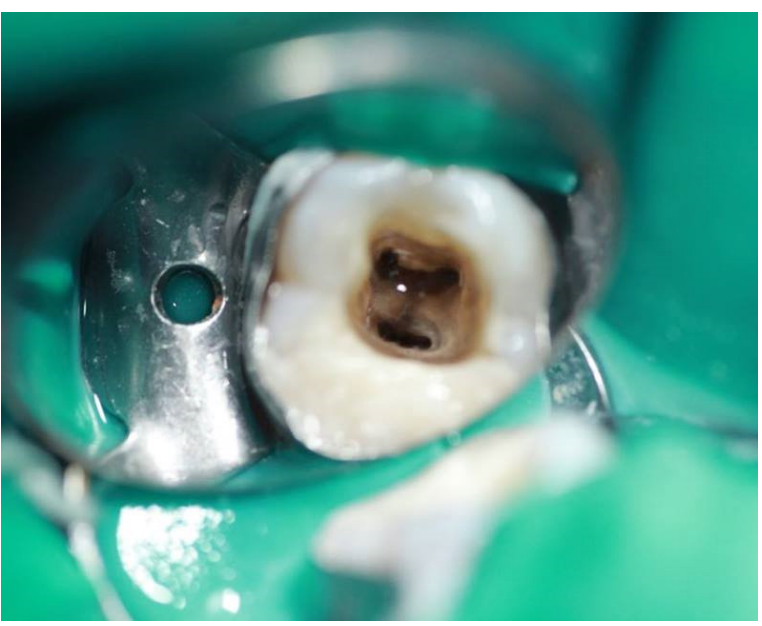

Fig. 4 Canal orifices of tooth 46 with four canals which are the mesio-buccal, mesio-lingual, distobuccal and disto-lingual canals.

After two weeks, the tooth 46 was asymptomatic and previous temporary restoration was removed. Root canals were irrigated again with $2.5 \% \mathrm{NaOCl}$ solution 
and final rinse with $17 \%$ EDTA solution. All 4 canals were obturated with gutta percha size 30 using single cone technique and EndoRez (Ultradent Products, Inc., South Jordan, UT, USA) sealer. Postoperative periapical radiograph (Fig. 5) was taken and universal composite resin (Filtek Z350 XT, $3 \mathrm{M}$ ESPE, USA) was used as permanent restoration (Fig. 6).

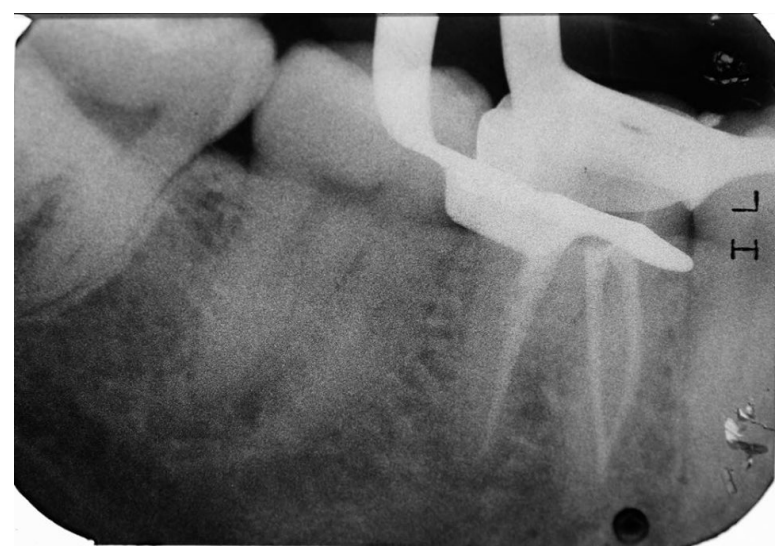

Fig. 5 Post operative radiograph of tooth 46 after obturation.

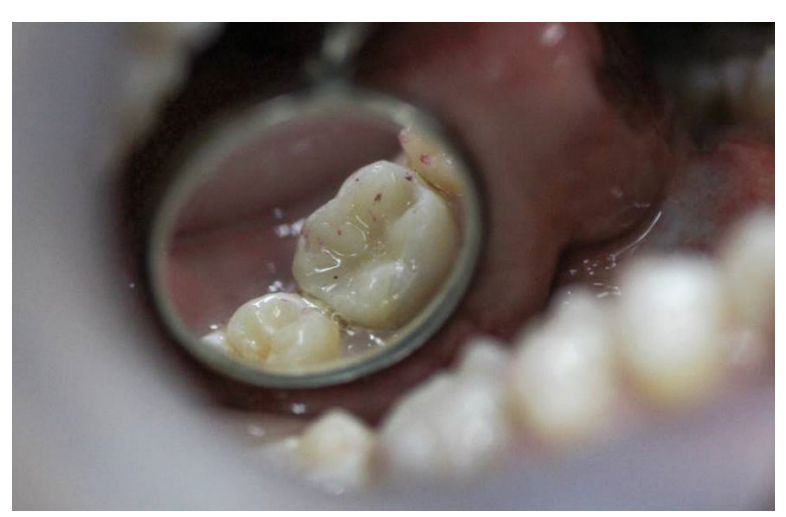

Fig. 6 Permanent composite resin restoration placed on tooth 46 .

The tooth remained asymptomatic after 1-month (Fig. 7) and 3-month (Fig. 8) follow-up periods. Clinically, there was no sign of swelling, inflammation or sinus tract noted around the gingiva. The tooth was non-tender to palpation and percussion with no mobility. Three months review radiographs also revealed no periapical pathology.

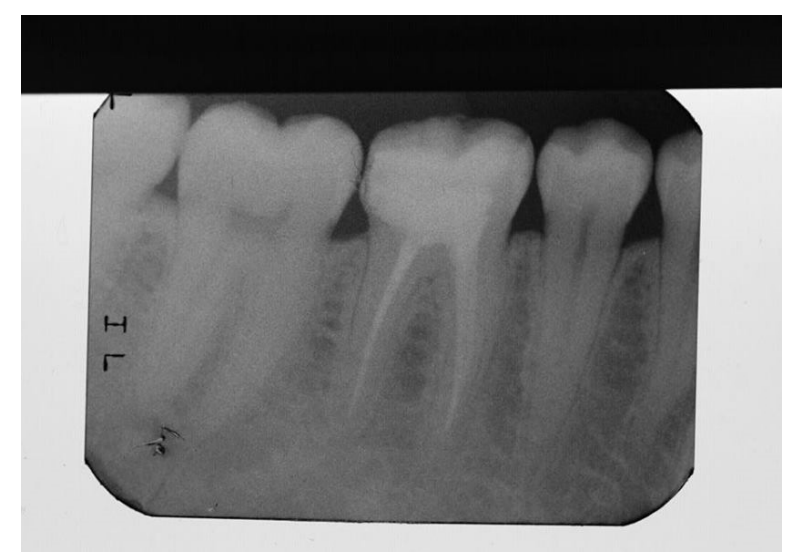

Fig. 7 Recall periapical radiograph after 1 month with no remarkable sign of periapical pathology.

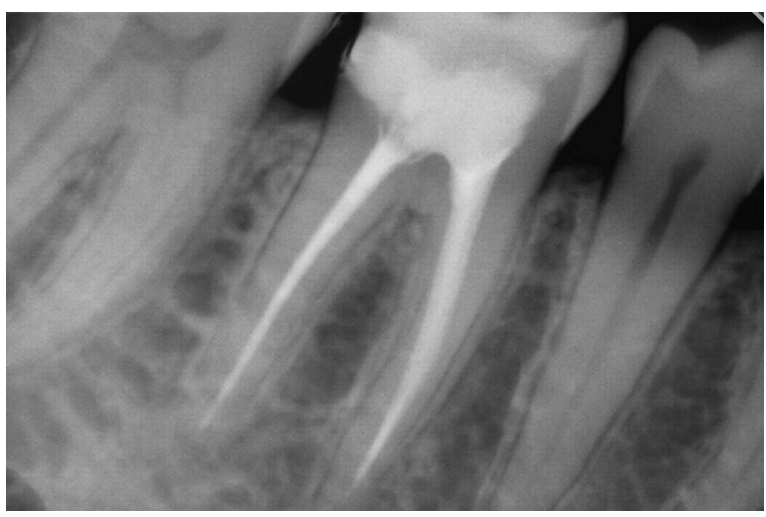

Fig. 8 Recall periapical radiograph after 3 months with no sign of periapical lesion.

\section{DISCUSSION}

Pulpotomy, a vital pulp therapy which involves the removal of coronal pulp, leaving remaining radicular pulp tissue covered with a dressing material that protects the pulp from further damage and also promotes healing of the pulpal tissue (Fuks, 2002). This vital pulp therapy was chosen in primary teeth and young permanent teeth with open apex rather than mature teeth with complete root formation due to their rich blood supply of the pulpal tissue, ability to respond to inflammatory reaction as well as higher success rate of tissue healing and regeneration with good long term prognosis (Fuks, 2000). On the other hand, mature permanent teeth with complete root 
formation have lower resistance to bacterial inflammation, reduction of pulpal cell populations and lower rate of pulpal vitality compared to immature permanent teeth (Takahashi, 1990). Hence, previous studies discouraged the practice of vital pulp therapy on mature permanent teeth and emphasised its negative aspects associated with lower success rate in mature permanent teeth (Ward, 2002).

Contrastingly, in the present case, the patient tooth retained its vitality for 20 years after complete pulpotomy was done. One of the possible explanations is the use of formocresol and zinc oxide eugenol as dressing materials. Formocresol, was one recommended as gold standard mummification agent in complete pulpotomy procedure. Formocresol will fix the radicular pulpal tissue by forming three layer zones of fixation: broad acidophilic zone; palestanding zone and zone of inflammatory cell, which forms a barrier to the irritant components of zinc oxide eugenol and acts as sub-base (Hume, 1986). Direct contact of zinc oxide eugenol with vital radicular pulp tissue will cause moderate to severe inflammatory responses which leads to chronic inflammation and eventually pulp necrosis. Age factor might not play an important role towards the long-term success in present case as studies revealed that vital pulp therapy showed promising results in patient age range from 6 to 70 years old due to the high healing capacity of pulp tissue in both young and old patients when carious lesion is removed (Ghoddusi et al., 2014). However, one of the possible reasons why patient presented with pulpitis symptoms could be attributed to the old twenty years tooth coloured restoration with compromised marginal seal which may leads to microleakage and bacterial invasion (Xie et al., 2008). Nowadays, management on mature permanent teeth has shifted towards a more conservative approach. Several studies have suggested MTA or Biodentine usage in partial or Cvek pulpotomy and even complete pulpotomy of mature permanent teeth. These provide a more realistic treatment modality for pulp exposures with high success rate (Taha et al., 2017). Pulpotomy in mature permanent teeth still remains one of the most controversial topics in dentistry and more long-term clinical studies may needed to provide reliable evidence base.

Calcified or sclerotic canals also known as pulp canal calcification (PCC), characterised as hard tissue deposited along the root canal walls and filled up most of the pulp canals. This causes the canals to be narrowed, restricted and jeopardised future endodontic treatment. The actual mechanism of this phenomenon is still unknown but studies believed that it is highly associated with complete pulpotomy procedure itself (Willard, 1976; Tziafas et al., 2000; Peng et al., 2006). Calcification of canals with formocresol pulpotomy is among the most common radiographic findings and it is reported in up to $80 \%$ of cases (Willard, 1976). This can be explained due to the inflammatory reaction between the vital radicular tissue and formocresol fixed tissue that forms reactionary dentine, followed by dentinal resorption and hard tissue deposition along the canal walls (Røolling and Lambjerg-Hansen, 1978). Another explanation can be due to the result of exaggerated odontoblastic or odontoblastlike cells activity. Based on several studies, the chance of pulp necrosis occurring from PCC is minimal after a period of observation for up to 22 years (Oginni and AdekoyaSofowora, 2007), but this only applies to primary and young permanent teeth.

Clinicians may face many challenges when performing root canal treatment on calcified canals as it increases the risk of perforation during an effort to negotiate the canals which may impair the prognosis of the tooth (Cvek et al., 1982). In cases where the root canals were considered severely calcified, they are considered difficult case according to American Association of Endodontists (Krastl et al., 2016). Some studies propose cone beam computed tomography (CBCT) usage to locate the canals (Krastl et al., 
2016), but in present case, only conventional periapical radiograph was used as a guide during endodontic procedures. It may not be impossible to perform root canal treatment on severely calcified canals with adequate knowledge on the morphology of root canal system. Once canal orifices were located, irrigation with $\mathrm{NaOCl}$ solution helped to remove most of the tissue and dentine debris, giving clear view of the canal orifices. In the present case, guide path was initiated using the smallest $\mathrm{K}$-file size after canal orifices were enlarged using HyFlex CM file no.1 with the help of chelating agent that effectively removed smear layers and made it easy to negotiate the calcified canals. The key in successfully negotiating calcified canals is frequent irrigation in the canals with endodontic irrigants. In the present case, $40 \mathrm{ml}$ of $2.5 \% \mathrm{NaOCl}$ solution was used to irrigate the canals because of its ability and efficiency to dissolve tissue debris (Naenni et al., 2004).

\section{CONCLUSION}

The present report described an unusual case of a pulpotomy treated mature mandibular first permanent molar that survived for 20 years. This report could provide a new insight to current research and suggest pulpotomy as treatment option for mature permanent teeth in a more conservative approach. However, long-term in vivo studies and clinical trials are needed to provide a reliable evidence base.

\section{REFERENCES}

Asgary S, Nourzadeh M, Eghbal MJ (2016). Miniature pulpotomy of symptomatic mature permanent teeth: A report of two cases. Iran Endod F, 11(1): 75-78. https://doi.org/10.7508/iej.2016.01.015.
Cvek M, Granath L, Lundberg M (1982). Failures and healing in endodontically treated non-vital anterior teeth with posttraumatically reduced pulpal lumen. Acta Odontol Scand, 40(4): 223-228. https:// doi.org/10.3109/00016358209019816.

Fong CD, Davis MJ (2002). Partial pulpotomy for immature permanent teeth, its present and future. Pediatr Dent, 24(1): 29-32.

Fuks AB (2000). Pulp therapy for the primary and young permanent dentitions. Dent Clin North Am, 44(3): 571-596.

Fuks AB (2002). Current concepts in vital primary pulp therapy. Eur $\mathcal{F}$ Paediatr Dent, 3(3): 115-120.

Ghoddusi J, Forghani M, Parisay I (2014). New approaches in vital pulp therapy in permanent teeth. Iran Endod F, 9(1): 15-22.

Gonzalez-Lara A, Ruiz-Rodriguez MS, PierdantPerez M, Garrocho-Rangel JA, PozosGuillen AJ (2016). Zinc oxide-eugenol pulpotomy in primary teeth: A 24-month follow-up. I Clin Pediatr Dent, 40(2): 107 112. https://doi.org/10.17796/1053-462840.2.107.

Hume WR (1986). The pharmacologic and toxicological properties of zinc oxideeugenol. If Am Dent Assoc, 113(5): 789-791. https://doi.org/10.14219/jada. archive.1986.0256.

Kang CM, Sun Y, Song JS, Pang NS, Roh BD et al. (2017). A randomized controlled trial of various MTA materials for partial pulpotomy in permanent teeth. $\mathcal{f}$ Dent, 60: 8-13. https://doi.org/10.1016/j. jdent.2016.07.015.

Krastl G, Zehnder MS, Connert T, Weiger R, Kühl S (2016). Guided endodontics: A novel treatment approach for teeth with pulp canal calcification and apical pathology. Dent Traumatol, 32(3): 240-246. https://doi.org/10.1111/edt.12235. 
Naenni N, Thoma K, Zehnder M (2004). Soft tissue dissolution capacity of currently used and potential endodontic irrigants. f Endod, 30(11): 785-787. https://doi. org/10.1097/00004770-200411000-00009.

Oginni AO, Adekoya-Sofowora CA (2007). Pulpal sequelae after trauma to anterior teeth among adult Nigerian dental patients. BMC Oral Health, 7:11. https://doi. org/10.1186/1472-6831-7-11.

Peng L, Ye L, Tan H, Zhou X (2006). Evaluation of the formocresol versus mineral trioxide aggregate primary molar pulpotomy: A meta-analysis. Oral Surg Oral Med Oral Pathol Oral Radiol Endod, 102(6): 40-44. https://doi.org/10.1016/j. tripleo.2006.05.017.

Røolling I, Lambjerg-Hansen H (1978). Pulp condition of successfully formocresoltreated primary molars. Scand $\mathcal{F}$ Dent Res, 86(4): 267-272.

Taha NA, Ahmad MB, Ghanim A (2017). Assessment of mineral trioxide aggregate pulpotomy in mature permanent teeth with carious exposures. Int Endod F, 50(2): 117125. https://doi.org/10.1111/iej.12605.

Taintor JF, Biesterfeld RC, Langeland K (1981). Irritational or reparative dentin. A challenge of nomenclature. Oral Surg Oral Med Oral Pathol, 51(4): 442-449. https:// doi.org/10.1016/0030-4220(81)90156-0.
Takahashi K (1990). Changes in the pulpal vasculature during inflammation. $\mathcal{F}$ Endod, 16(2): 92-97.

Tchaou WS, Turng BF, Minah GE, Coll JA (1995). In vitro inhibition of bacteria from root canals of primary teeth by various dental materials. Pediatr Dent, 17(5): 351355.

Tziafas D, Smith AJ, Lesot H (2000). Designing new treatment strategies in vital pulp therapy. F Dent, 28(2): 77-92. https://doi. org/10.1016/S0300-5712(99)00047-0.

Ward J (2002). Vital pulp therapy in cariously exposed permanent teeth and its limitations. Aust Endod F, 28(1): 29-37. https://doi.org/10.1111/j.1747-4477.2002. tb00364.x.

Willard RM (1976). Radiographic changes following formocresol pulpotomy in primary molars. ASDC $\mathcal{F}$ Dent Child, 43(6): 414-415.

Xie H, Zhang F, Wu Y, Chen C, Liu W (2008). Dentine bond strength and microleakage of flowable composite, compomer and glass ionomer cement. Aust Dent F, 53(4): 325-331. https://doi.org/10.1111/j.18347819.2008.00074.x. 